\title{
Understanding Proximity Mobile Payment Acceptance among Saudi Individuals: An Exploratory Study
}

\author{
Rana Alabdan ${ }^{1}$ \\ Department of Information Systems \\ College of Computer and Information Sciences \\ Majmaah University, Al Majmaah 11952, Saudi Arabia
}

\author{
Sulphey $\mathrm{MM}^{2}$ \\ Department of Human Resources \\ College of Business Administration \\ Prince Sattam bin Abdulaziz University
}

\begin{abstract}
The electronic method of payments such as cash, debit, or credit as the new method of mobile payment, which is a paradigm shift in the pattern payment. Mobile payment is increasingly an essential electronic service in the banking sector, which also plays a competitive advantage among banks. Although mobile payment has gradually been accepted in Saudi Arabia, limited research has been conducted to explore the barriers to accepting mobile payment among Saudi nationals. This study examined the factors of mobile payment acceptance among Saudis. An online survey was conducted among 414 respondents. The study has succeeded in identifying Ease of Use, Utility, Security, and Awareness as the factors that could result in accepting mobile payment options. It is also found that male respondents have better mobile acceptance than females. A few suggestions to enhance mobile acceptance among the Saudi population are also provided. It is anticipated that the present study will act as a trigger for further studies in this noteworthy area.
\end{abstract}

Keywords-Awareness; mobile payment; Saudi; quantitative study; e-payment; banking; ease of use

\section{INTRODUCTION}

In the recent past, the usage of smartphones has grown exponentially in Saudi Arabia. According to [35], smartphones were used widely among Saudi users, 19 millions of users in 2015 and then increased to 21 in 2018. It is also estimated to reach approximately 24 million by 2022 . According to figures provided by [15], the ratio of usage among males and females stood at $70.52 \%$ and $62.15 \%$, respectively. The usage of the internet is also high in the country. The ratio of internet usage among males and females is assessed to be at $91.54 \%$ and $90.46 \%$, respectively [15]. It is reported that Saudis use the Internet at least once a day. However, according to [15], the usage of electronic banking services is $11.10 \%$. The ratio of online trade is also found to be at a meager rate of $6.18 \%$. This shows that, even though there is a high proliferation of internet usage among Saudi nationals, the usage of smartphones for mobile payment is still at a relatively low level. There is a definite need to look at this aspect in detail.

It is expected that mobile payment will increase gradually due to the high usage of smartphones and the emergence of new technology. Several research works have examined this aspect (for instance, [29], [31]). There is a vast difference between mobile payment and online banking. Mobile payment was defined as "movement of value that is made from a mobile wallet, accrues to a mobile wallet, and is initiated using a mobile phone" (as cited in [29] p. 1). To understand mobile payment, there is also a need to define online banking. Online banking was defined as "the way of providing products and services through electronic channels instead of physical-only bank provision of banking products and services through electronic delivery channels" ([9] p. 19). The present study aims to explore the various factors that impact Saudi nationals to accept mobile payment in Saudi Arabia. The literature review has focused on the various factors that are capable of influencing mobile payment, acceptance of mobile payment, and trust and security issues. The research questions identified for this study are:

- RQ1: What are the factors that influence the acceptance of mobile payment by Saudi individuals?

- RQ2: Is there a gender effect on Saudi individuals in accepting mobile payment?

- RQ3: What can be done to encourage Saudis to accept mobile payments?

This study structured as follows: an introduction followed by the literature review. The review of literature has two sections - factors that impact mobile payment acceptance followed by trust in mobile payments. This is followed by the methodology, discussion, and analysis. The findings of the study are discussed in the results section. The last section presents the implications followed by the limitation of this study.

\section{RELATED WORK}

The topic of mobile adoption for electronic banking services is widely researched, and there exists adequate literature regarding this type of banking. After surveying the literature, it presents a vast majority of researchers have used the Technology Acceptance Model (TAM) to investigate mobile payment systems (e.g. [4], [5], [10], [24], [31]). Studies about mobile payment and TAM have been found to have originated in the current decade. Since TAM is found to have received wide acceptance, the present work also intends to focus mostly on this theoretical framework, though other models have also been found used. 
An early study was conducted by [24] in Korea with a sample of 269. The researchers collected the data through interviews and e-mails. The study adopted a unique methodology wherein a differentiation was made between primary and new adopters of mobile payment. Kim's study found that primary adopters were influenced by the ease of use. However, new adopters were influenced by the usefulness, convenience, and reachability of mobile payment. Though mobility and reachability were found to affect the ease of use for early adopters, the aspect of usefulness was not given due consideration as the users did not expect much use of this service. However, for late adopters, reachability was found to affect both usefulness and the perceived ease of use. Also, [8] assessed the various factors that influence mobile payment acceptance services among students. Based on an online survey conducted amongst a sample of 441 respondents from Tanzania, they found that multiple factors influenced behavior to adopt mobile payment. They included performance expectancy, effort expectance, and social influence.

Furthermore, [10] conducted a study using TAM to investigate the factors which could influence the adoption of mobile payment in Turkey. The study concluded trust, attitude, and mobility positively influenced mobile payment. Another significant finding of the study was that ease of use and usefulness did not affect mobile payment. Also, [7] investigated the significant factors impact trust in mobile payment within Iran. Using questioner which is distributed via Internet, they collected data from a sample of 246. The study found that consumers perceived that the security of transactions need to be improved. They opined that mobile payment acceptance might be enhanced by strict adherence to guidelines' security, technical, and transaction procedures. Trust is found to be the most significant factor that influenced the acceptance of the service. Security was also found to have a strong positive effect on mobile payment adoption. In a study in Tanzania, [29] investigated the users' behavioral intention to use mobile payment services. The study identified the influence of security, user-centric, system characteristics, and gender effects on mobile acceptance. A study [2] in Saudi Arabia explored the factors of mobile payment acceptance in Majmaah University among faculty, staff, and students; security found to be the only factor that influences the community in the University.

Likewise, [28] examined the acceptance of Near-field communication technology (NFC) for mobile payment within Brazil. They explored the factors that influence the usage of NFC directly or indirectly. The study employed data from a sample of 423. The researchers proved the user's willingness was influenced by the use of information technology (IT), usefulness, and innovation. It was also found that with NFC technology, the willingness to use stood at $74 \%$. This was followed by personal innovation in IT at $56 \%$ and perceived usefulness at $43 \%$. The study by [4] using TAM revolved around factors such as anxiety, privacy, technology, and selfefficacy in the usage of mobile payment. The study, conducted in the United States, found that mobile payments were influenced by the following factors: self-efficacy, intention to use it, ease of use, usefulness, and privacy concerns.
A recent study by [23] investigated the adoption of mobile payment using the technology-organization-environment TOE framework, addressing technological, organizational, and environmental factors. The researchers used structural equation modeling (SEM) to analyze the relationships within the framework. They identified that external factors like pressures from customers, relative advantage, top management support, and user benefit from innovation influenced mobile payment adoption.

\section{A. Factors of Mobile Adoption}

The factors identified by the researchers included security [26], [34], simplicity [26], [34], acceptance [30], [34], usability [16], [34], and efficiency [1], [24]. The endurance towards the adoption of mobile payment has also been a matter of empirical investigation. For instance, [27] scrutinized the adoption of mobile payment via PayPal in Malaysia and the reasons behind the resistance to adopting such service among generation X (born between 1961 and 1981). The researcher used Innovation Resistance Theory (IRT) to investigate the barriers of mobile adoption. IRT has been rarely used among researchers in mobile payment studies. The barriers identified by the study include cost, tradition, image, value, risk, and usage.

An overview of the studies shows that [24] investigated mobile payment from a different perspective. The scholars investigated early and late adopters to mobile payment, and they did not incorporate the behavior of the adopters into the TAM model. The study was limited to a few factors and did not investigate certain other factors like self-efficacy, accessibility, localization, etc. It can be seen that [29] investigated the aspect of mobile payment from users' behavioral perspective towards the service. They found that gender was a strong factor that influenced mobile payment adoption, with males being influenced by innovativeness and compatibility females being influenced by social pressure and usefulness of service. This points to the need for banks to consider the aspect of gender.

\section{B. Trust and Security Aspects of Mobile Payment}

A study by [33] studied the barriers among US students to embrace mobile payment services. The researchers ascertained availability, security, and awareness as the influential factors to adopt mobile payment. It investigated the barriers instead of the non-adoption of mobile payment services, which is the opposite of what other researchers use to conduct. As researchers focused on the factors of adoption or acceptance, which emphasize the importance of this study. Trust is a crucial factor that influences mobile payment usage and is a barrier that prevents mobile payments from being broadly used. Furthermore, [14] indicated the long-term barrier for mobile payment is a lack of user trust. The researchers disseminated a survey among 1155 within Australia. They debated the system quality and information are correlated to trust as a positive effective factor. Thus, mobile payment usage is affected by trust positively, which perceived as a convenience. [5] emphasized the prominence of trust as the main factor in adopting mobile payment. Three main factors influenced Trust as the following: accessibility of security guidelines, usability, transaction, and technical procedures. 
The users' attitude regarding mobile payment differs between new adopters and existing users. The new adopters have some doubts about mobile payment services, whereas existing users have more trust in these services. In [18] focused on their research on two different groups of users. Two groups, one buy through online and the other buy only form the physical store. Hence, the first group had no issue with online mobile payment, while the second group had trust issues adopting such technology [2] [18].

Similarly, [25] investigated the security issues in the Hungarian electronic banking systems and recommended the Bank should revise the payment services regulations internationally and locally. A fraud incident alerted the Bank to raise multiple questions regarding security and how to protect electronic payments. They added internal security measures to cover all processes of electronic transactions. The customer attitudes regarding such incidents increase awareness among the users to protect their bank's information.

Several researchers, such as [5], [14], [18], [25], emphasized the significance of trust as a factor that influences users on the adoption of mobile payments. The companies and banks that use mobile payment need to improve the level of trust in mobile payment services. The usage will be improved when the level of trust is increased. Individuals might avoid mobile payment because of the security risk, were they afraid to lose some sensitive financial information while using these services. Therefore, this research was conducted to investigate the barriers that affect the acceptance of mobile payments among Saudi nationals and how to encourage them to adopt this service. There are limited studies regards this topic, which is specifically targeted at barriers to mobile payment adoption in Saudi Arabia.

From the objective review, it was found that mobile payment adoption varied based on the usage of this service, by the sample of individuals chosen and the gender. The major influencing factors identified include ease of use [4], [24], usefulness [4], [24], [28], [29], perceived security risks [5], [25], [33], awareness [14], and trust [14], [18], [25]. However, there could also be secondary factors that may affect the adoption of mobile payments. To conclude, the previous researches recommend that mobile payment services have barriers in which it influences the acceptance of this technology. The barriers are lack of awareness, lack of availability, deficient ease of use, and perceived security risks. For a better understanding, the review details are presented in Table I.

Studies have originated from Saudi Arabia regarding mobile payment adoption [1]. The study by [1] developed a framework for Saudi Payment Network (SPAN), which recommended a solution to the mobile payment infrastructure in Saudi's mobile payment system. This system was developed based on the success factors arrived at from the available literature.
TABLE I. SUMMARy OF THE MOBILE PAYMENT ACCEPTANCE FACTORS IN THE LITERATURE

\begin{tabular}{|l|l|}
\hline Factors & Construct \\
\hline Simplicity / Ease of use & {$[4],[24],[26],[34]$} \\
\hline Awareness & {$[13]$} \\
\hline Trust & {$[14],[18],[25]$} \\
\hline Security & {$[26],[34],[2]$} \\
\hline Performance & {$[26],[34]$} \\
\hline Interoperability & {$[1],[26],[34]$} \\
\hline Cost effective & {$[22],[34]$} \\
\hline Acceptance & {$[30],[34]$} \\
\hline Usability & {$[16],[34]$} \\
\hline Efficiency & {$[1],[26]$} \\
\hline Usefulness & {$[4],[24],[28],[29]$} \\
\hline
\end{tabular}

\section{Methodology}

The total population of Saudi Arabia as of December 2018 was $13,161,020$ [15]. The study sample should be 385 to reach the required satisfaction level according to the equation that calculates the sample size $=$

$$
\frac{\frac{\left(\mathrm{z}^{2} \times \mathrm{p}(1-\mathrm{p})\right)}{\mathrm{e}^{2}}}{1+\left(\frac{\mathrm{z}^{2 \times \mathrm{p}(1-\mathrm{p})}}{\mathrm{e}^{2} \mathrm{~N}}\right)}
$$

$\mathrm{N}=$ population size, $\mathrm{e}=$ Margin of error (percentage in decimal form), $\mathrm{z}=\mathrm{z}$-score (SurveyMonkey).

The present study was conducted with a sample of 414 . With this number of respondents, this study becomes the largest to date that investigates barriers to mobile payment acceptance in Saudi Arabia. This survey was conducted online. The research questions were distributed into three parts, organized as the following:

1) Demographic: Exploring the participants' demographic characteristics, including issues related to age, gender, area, mobile type, education level, and income in Saudi Riyal.

2) General questions about mobile payment services.

3) Items regarding the acceptance of mobile payment services in Saudi Arabia.

Data were collected from a total of 414 samples spreads across Saudi Arabia for mobile payment users. Before distributing the survey, the required ethical approval was obtained from the Deanship of Scientific Research at Majmaah University. Based on the sample size, the Kaiser-Meyer-Olkin Measure of Sampling Adequacy was found to be 0.695 . The Bartlett's Test of Sphericity was found to be 880.018 , which was significant $(0.000)$. This shows that the sample collected was adequate. Table II provides the demographic details of the respondents. 
TABLE II. THE SUMMARY OF RESPONDENTS’ DEMOGRAPHIC CHARACTERISTICS

\begin{tabular}{|c|c|c|c|}
\hline Demographics & Characteristic & Count & Percentage \\
\hline \multirow{2}{*}{ Gender } & Female & 144 & $34.78 \%$ \\
\hline & Male & 270 & $65.22 \%$ \\
\hline \multirow{5}{*}{ Age (in years) } & $18-29$ & 90 & $21.74 \%$ \\
\hline & $30-39$ & 172 & $41.55 \%$ \\
\hline & $40-49$ & 105 & $25.36 \%$ \\
\hline & $50-59$ & 38 & $9.18 \%$ \\
\hline & $60+$ & 9 & $2.17 \%$ \\
\hline \multirow{5}{*}{ Employment Status } & Public Employed & 151 & $36.47 \%$ \\
\hline & Private Employed & 152 & $36.71 \%$ \\
\hline & Self-employed & 31 & $7.49 \%$ \\
\hline & Student & 40 & $9.66 \%$ \\
\hline & Other & 40 & $9.66 \%$ \\
\hline \multirow{5}{*}{ Education Level } & High school & 38 & $9.18 \%$ \\
\hline & Post-secondary Diploma & 35 & $8.45 \%$ \\
\hline & Bachelor degree & 180 & $43.48 \%$ \\
\hline & Master degree & 112 & $27.05 \%$ \\
\hline & $\mathrm{PhD}$ degree & 49 & $11.84 \%$ \\
\hline \multirow{3}{*}{ Phone Type } & iPhone & 309 & $74.64 \%$ \\
\hline & Android & 101 & $24.40 \%$ \\
\hline & Other & 4 & $0.96 \%$ \\
\hline \multirow{6}{*}{ Income } & $30,000-39,999 \mathrm{SR}$ & 85 & $20.53 \%$ \\
\hline & $40,000-49,999 \mathrm{SR}$ & 28 & $6.76 \%$ \\
\hline & $50,000-74,999 \mathrm{SR}$ & 38 & $9.18 \%$ \\
\hline & $75,000-99,999$ SR & 35 & $8.45 \%$ \\
\hline & $100,000-150,000 \mathrm{SR}$ & 73 & $17.63 \%$ \\
\hline & More than 150,000 & 155 & $37.44 \%$ \\
\hline
\end{tabular}

65.22 percent of the respondents were males. In this context, this survey was distributed online without targeting particular groups, and there is no specific reason for the higher male response. The majority of the respondents were in the 3039 age group (41.55 percent), with the maximum number employed either in public or private (73.18 percent). Bachelor degree holders constituted the maximum with 43.48 percent. Based on the diversity of the data collected, it can be construed that it is representative, and is capable of arriving at unbiased results. The vast difference was also observed concerning the type of mobile phone used, employment status, and income levels of the sample.

\section{A. Data Collection Tool}

The questionnaire for data collection was prepared based on three main domains: awareness, availability, and security. These domains and the item pool were created based on the study of [33]. An item pool consisting of 15 items were created. However, based on expert opinion, four questions were dropped, thereby retaining a total of 11 items, which were used for the study. There are studies regarding a few other factors of mobile payment like usefulness, ease of use, and trust, and this study will focus on the awareness, availability, security, and ease of use, etc. The survey used a five-point Likert scale: strongly agree, agree, neutral, disagree, and strongly disagree. This scaling is applicable as it increases response rate, quality, and to be more comfortable to the participants [6], [11]. A convenience sample was used to collect the required data [3]. The example involved respondents over 18 years, including various generations and job status. The diversity in the sample would support to have representative data.

\section{B. Tool Refinement}

The data collection tool was refined using time tested procedures like item reduction, evaluation, estimation of internal consistency, etc. The details are presented in the following sections.

1) Item reduction: of the different statistical techniques recommended for item refining and reduction, the present study used inter-item correlation and factor analysis [7], [19], [20]. For instance, [7] believes that items could be eliminated if the inter-item correlation of any item exceeds 0.70. According to him, "this could help in avoiding too much redundancy and artificially inflated estimates of internal consistency" ([7] p. 347). Since none of the R-values exceeded 0.70 , no elimination was warranted.

The 11 items identified for the study were subjected to Factor analysis (FA). FA for the study was done with Varimax rotation and Kaiser Normalization. The rotations converged at 12 iterations. The rotated factor matrix presented a four-factor solution that emerged with a cumulative loading of $62.18 \%$, which is acceptable. The minimum stipulated loading for FA is 0.40 [12], [20]. All the items were found to have loadings above 0.40 . However, one thing had to eliminated as it had cross-loading. This resulted in a tool consisting of 10 questions. The details are presented in Table III.

\section{Tool Evaluation}

Evaluation of the tool was done through assessment of reliability, internal consistency, and validities.

1) Estimation of internal consistency reliability: Inter-item correlation and Cronbach's Alpha are the standard methods used to assess safety. Author in [32] suggested a Cronbach Alpha standard of 0.70 for internal consistency. The Alpha for the present study was 0.681 . Though this is below the threshold value of 0.70 , the research being exploratory, this value can be considered as acceptable [32]. This relaxation in Cronbach Alpha has also been confirmed by earlier studies of [13] and [21]. For inter-item correlation, the rule of the thumb is that the relationships need to exceed the threshold value of 0.30 [17], which has been met for the present study. Further, the item-tototal correlations have to exceed 0.50 . The item to the total relationship is presented in Table III, which exceeds the stipulated 0.50. Thus, the criterion specified for internal consistency reliability by [17] is met. These confirm the safety of the tool. Further, the overall mean of the scale was 31.09, and the standard deviation was 5.71. 
TABLE III. FACTOR ANALYSIS

\begin{tabular}{|c|c|c|}
\hline Items & Loading & ITC $^{\mathrm{a}}$ \\
\hline \multicolumn{3}{|l|}{ Factor 1: Ease of Use } \\
\hline $\begin{array}{l}\text { 1. I think mobile payment services are simple to } \\
\text { understand and use on my smartphone [2] } \\
\text { [33]. }\end{array}$ & 0.673 & 0.789 \\
\hline $\begin{array}{l}\text { 2. I think mobile payments are accepted by } \\
\text { enough retailers to make their use } \\
\text { worthwhile [2] [33]. }\end{array}$ & 0.829 & 0.824 \\
\hline $\begin{array}{l}\text { 3. I think that my personal payment information } \\
\text { is kept safe when I use a mobile payment } \\
\text { service to pay for a purchase [2] [33]. }\end{array}$ & 0.734 & 0.765 \\
\hline Mean & \multicolumn{2}{|l|}{10.81} \\
\hline Standard deviation & \multicolumn{2}{|l|}{2.60} \\
\hline \multicolumn{3}{|l|}{ Factor 2: Utility } \\
\hline $\begin{array}{l}\text { 4. It is difficult to set up and use mobile } \\
\text { payment services [2] [33]. }\end{array}$ & 0.644 & 0.681 \\
\hline $\begin{array}{l}\text { 5. The places I shop don't accept mobile } \\
\text { payments [2] [33]. }\end{array}$ & 0.746 & 0.618 \\
\hline $\begin{array}{l}\text { 6. It is easier for me to pay with cash or a } \\
\text { credit/debit card than to use mobile } \\
\text { payment services [2] [33]. }\end{array}$ & 0.541 & 0.734 \\
\hline Mean & \multicolumn{2}{|l|}{8.50} \\
\hline Standard deviation & \multicolumn{2}{|l|}{2.17} \\
\hline \multicolumn{3}{|l|}{ Factor 3: Security } \\
\hline $\begin{array}{l}\text { 7. I am concerned about the security of mobile } \\
\text { payments [2] [33]. }\end{array}$ & 0.847 & 0.926 \\
\hline $\begin{array}{l}\text { 8. I am concerned about someone intercepting } \\
\text { my payment information or other data if I } \\
\text { use mobile payment services [2] [33]. }\end{array}$ & 0.872 & 0.927 \\
\hline Mean & \multicolumn{2}{|l|}{4.97} \\
\hline Standard deviation & \multicolumn{2}{|l|}{2.24} \\
\hline \multicolumn{3}{|l|}{ Factor 4: Awareness } \\
\hline $\begin{array}{l}\text { 9. I don't understand all the different mobile } \\
\text { payment options [2] [33]. }\end{array}$ & 0.657 & 0.787 \\
\hline $\begin{array}{l}\text { 10.I know how to use mobile payment services } \\
\text { on my smartphone [2] [33]. }\end{array}$ & 0.619 & 0.780 \\
\hline Mean & \multicolumn{2}{|l|}{6.81} \\
\hline Standard deviation & \multicolumn{2}{|l|}{1.76} \\
\hline
\end{tabular}

b. All correlations are significant at the 0.01 level.

\section{ANALYSIS AND DISCUSSION}

Previous researches on mobile payments have not fully examined the factors that influenced the acceptance of this service by Saudi nationals. To fill this research gap, this study used constructs from previous studies [4], [16], [28], [29], [34]. It was based on this that the first research question was framed. The first research question was to identify the factors that influence the acceptance of mobile payment by Saudi individuals. The FA has helped in identifying four influencing factors (Table III). It can thus be considered that Ease of use, Utility, Security, and Awareness are the factors that influence the acceptance of mobile payment among Saudi nationals. This finding is partially in tandem with the studies of [4], [5], [14], [33].
The second research question identified for the study was the gender effect on Saudi nationals in accepting mobile payment. T-test was conducted to find out if there existed any difference in mobile payment acceptance based on gender, and the results are presented in Table IV.

It can be observed that the $t$-value for mobile acceptance is 4.050, which is significant at the 0.01 level. This indicates that there is a significant difference between males and females concerning mobile acceptance. Since the overall mean value of males is higher (31.90) than females (29.56), it can be stated that they have better mobile payment adaption. An earlier study by [29] found gender to be a strong factor that influenced mobile payment acceptance. They had observed that males were influenced by innovativeness and compatibility, while females were influenced by social pressure and usefulness of service. The results of the present study partially substantiate the findings of [29]. A close look at the different factors revealed that other than for Utility, where there was no significant difference based on gender. All the other factors (Ease of Use, Security, and Awareness) showed a significant difference based on gender, with males having higher mean scores than females. This finding is indeed noteworthy, which could be attributed to the unique social structure prevalent in Saudi Arabia. This is an aspect that has not been examined by earlier studies.

This study has succeeded in identifying the factors that influence mobile payment acceptance. These factors were also identified in earlier studies (for instance, [5], [25], [29], [33]).

The third research question was to identify aspects that could encourage Saudis to adopt mobile payments. The identified factors are pointers to this research question. All four factors need to be addressed if mobile payments are to be encouraged among Saudi nationals. The mobile payment should have ease of use. It should be simple and should be capable of being used by any individual. Thus, to encourage Saudis to adopt such services, mobile payments should be available everywhere in stores and retails to increase usage of this service. Another aspect is Utility, it should be available locally and in all stores were customers are likely to visit for their routine requirements.

TABLE IV. DATA AND T-VALUe BASED ON GENDER OF THE RESPONDENTS

\begin{tabular}{|c|c|c|c|c|c|}
\hline & Gender & $\mathbf{N}$ & Mean & $\begin{array}{l}\text { Std. } \\
\text { Deviation }\end{array}$ & t-value \\
\hline \multirow{2}{*}{$\begin{array}{l}\text { Ease of } \\
\text { use }\end{array}$} & Male & 270 & 11.09 & 2.646 & \multirow{2}{*}{2.996 ** } \\
\hline & Female & 144 & 10.29 & 2.446 & \\
\hline \multirow{2}{*}{ Utility } & Male & 270 & 8.50 & 2.198 & \multirow{2}{*}{$0.17 *$} \\
\hline & Female & 144 & 8.50 & 2.125 & \\
\hline \multirow{2}{*}{ Security } & Male & 270 & 5.26 & 2.307 & \multirow{2}{*}{3.619 ** } \\
\hline & Female & 144 & 4.43 & 2.013 & \\
\hline \multirow{2}{*}{ Awareness } & Male & 270 & 7.06 & 1.703 & \multirow{2}{*}{$4.001 * *$} \\
\hline & Female & 144 & 6.34 & 1.786 & \\
\hline \multirow{2}{*}{ TOTAL } & Male & 270 & 31.90 & 5.843 & \multirow{2}{*}{$4.050 * *$} \\
\hline & Female & 144 & 29.56 & 5.119 & \\
\hline
\end{tabular}


Security has also been identified as a factor. It is human nature that people are worried about the security aspect of their money. As such, this aspect needs to be given due and adequate importance if people are to be motivated to involve in mobile payment options. Thus, Saudi banks need to provide a solid method of security for online services, which will increase the trust of security within Saudi individuals. Further, the evidence must be provided to the extent that mobile payments have strong security, and is supported by the Saudi Arabian Monetary Agency (SAMA).

Furthermore, the fourth factor that can motivate people to involve in mobile payment is Awareness. They should be provided with the required awareness about all aspects of mobile payment. This could include how to use, what to do in the event of a faulty payment, the rectification of errors, etc. If all these factors are given due and adequate consideration and importance, there is no reason why people could be motivated in involving in mobile payments. If banks, traders, and associated stakeholders consider these aspects, it is possible to add more customers. Further, the unit cost of payments will also come down drastically, benefitting all concerned.

The main limitation of the study is that it has been limited to formally educated people. The majority of respondents hold a Bachelor's (43.48\%) or Master's (27.05\%) degree. Educated people may be more inclined to use mobile payment technology. Further studies need to be conducted to focus on the cross-section of the population. Additionally, future research can also be undertaken to study the impact of cultural factors on the attitudes of Saudi nationals toward mobile payment.

\section{CONCLUSION}

This study was conducted to investigate the factors and barriers that affect the mobile payment acceptance services in the Kingdom of Saudi Arabia. A survey distributed among Saudi mobile payment users to address the factor that influences the acceptance and the usage of this service. In this study, it was observed that the majority of participants (373 $90 \%$ ) are willing to use mobile payment services. Moreover, the majority of participants (306-75\%) agree that mobile payment services are easy to understand; a majority of previous researchers acknowledged the same [24], [10], [4]. The research has also identified that security issues have to be taken into account to encourage Saudi nationals to use this service, this result agreed with [2] study which identified security as a factor, too. Further, approximately $45 \%$ of the participants claim that many stores fail to accept mobile payments. This might be a challenge in the use of this service in Saudi Arabia.

Further research has to be focused on how to provide mobile payment security with more effective awareness. It is expected that this humble work will act as a trigger for further work in this magnificent and fertile area of research.

\section{REFERENCES}

[1] A. S. Abanmi, Mobile payment in Saudi Arabia, Ph.D. dissertation, Prince Sultan University, Riyadh, Saudi Arabia, 2015.

[2] R. Alabdan, Exploring barriers to mobile payments adoption: A case study of Majmaah University in Saudi Arabia, in Proceedings International Conference on Computing, Cham, Switzerland, 2019, pp. 144-160.
[3] E. Babbie, Survey Research Methods (2nd ed.). Belmont, CA: Wadsworth, 1990.

[4] A. Bailey, I. Pentina, A. S. Mishra, and M. S. Ben Mimoun, Mobile payments adoption by US consumers: An extended TAM, International Journal of Retail \& Distribution Management, vol. 45. no. 6, pp. 626640, 2017.

[5] M. Barkhordari, Z. Nourollah, H. Mashayekhi, Y. Mashayekhi, and M. S. Ahangar, Factors influencing adoption of e-payment systems: An empirical study on Iranian customers, Information Systems and eBusiness Management, vol. 1, no.1, pp. 89-116, 2017.

[6] N. Bouranta, L. Chitiris, and J. Paravantis, The relationship between internal and external service quality, International Journal of Contemporary Hospitality Management, vol. 21, no. 3, pp. 275-293, 2009.

[7] G. J. Boyle, Does item homogeneity indicate internal inconsistency or item redundancy in psychometric scales? Personality and Individual Differences, vol. 12, no. 3, pp. 291-294, 1991.

[8] B. Chachage, F. Kamuzora, and G. Malima, Factors influencing acceptance of mobile money services amongst students of higher learning institutions in Tanzania with special reference to Ruaha University college, International Journal of Management, vol. 2, no. 2, pp. 9-18, 2013.

[9] J. Chavan, Internet banking-Benefits and challenges in an emerging economy, International Journal of Research in Business Management, vol. 1, no.1, pp. 19-26, 2013.

[10] I. Dastan and C. Gürler, Factors affecting the adoption of mobile payment systems: An empirical analysis, Emerging Markets Journal, vol. 6 , no. 1, pp. 17-24, 2016.

[11] J. Dawes. Do data characteristics change according to the number of scale points used? An experiment using 5-point, 7-point and 10-point scales. International journal of market research, vol 50, no. 1, pp.61-104, 2008.

[12] J. K. Ford, R. C. MacCallum, and M. Tait, The application of exploratory factor analysis in applied psychology: A critical review and analysis, Personnel Psychology, vol. 39, pp. 291-314, 1986.

[13] K. N. Gaertner and S. D. Nollen, Career experiences, perceptions of employment practices, and psychological commitment to the organization, Human Relations, vol. 42, no. 1, pp. 975-991, 1989.

[14] L. Gao and K. A. Waechter, Examining the role of initial trust in user adoption of mobile payment services: An empirical investigation, Information Systems Frontiers, vol. 19, no. 3, pp. 525-548, 2017.

[15] General Authority of Statistics (GAS). (2018). Survey of ICT access to households and individuals. [Online]. Available: https://www.stats.gov. sa/en/survey/13502

[16] C. Gu and Y. Ye, The impact factors and model analysis of mobile payment service under the background of 3G, in Proceedings 2011 International Conference of Information Technology, Computer Engineering and Management Sciences (ICM 2011), Nanjing, Jiangsu, China, 2011, vol. 4, pp. 89-92.

[17] J. F. Hair, W. C. Black, B. J. Babin, R. E. Anderson, and R. L. Tatham, Multivariate data analysis, vol. 6, Upper Saddle River, NJ: Pearson Prentice Hall, 2006.

[18] S. Hillman and C. Neustaedter, Trust and mobile commerce in North America. Computers in Human Behavior, vol. 70, pp.10-21, 2017.

[19] T. R. Hinkin, A brief tutorial on the development of measures for use in survey questionnaires, Organizational Research Methods, vol. 1, 104121, 1998.

[20] T. R. Hinkin, A review of scale development practices in the study of organizations, Journal of Management, vol. 21, no. 5, pp. 967-988, 1995.

[21] D. T. Holt, A. A. Armenakis, H. S. Field, and S. G. Harris, Readiness for organizational change: The systematic development of a scale, Journal of Applied Behavioral Science, vol. 43, no. 2, pp. 232-255, 2007.

[22] P. Hongxia, X. Xianhao, Xand L. I. U. Weidan, Drivers and barriers in the acceptance of mobile payment in China, in Proceedings 2011 International Conference on E-business and E-government (ICEE), Shanghai, China, 2011, pp. 1-4. 
[23] A.N. Khan and A. Ali, Factors affecting retailer's adopti on of mobile payment systems: A SEM-neural network modeling approach. Wireless Personal Communications, vol. 103, no. 3, pp.2529-2551, 2018.

[24] C. Kim, M. Mirusmonov, and I. Lee, An empirical examination of factors influencing the intention to use mobile payment, Computers in Human Behavior, vol. 26, no. 3, pp. 310-322, 2010.

[25] L. Kovács and S. David, Fraud risk in electronic payment transactions, Journal of Money Laundering Control, vol. 19, no. 2, pp. 148-157, 2016.

[26] G. Lao and H. Liu, Study of mobile payment business model based on third-party mobile payment service provider, in Proceedings 2011 International Conference on Management and Service Science, Wuhan, China, 2011, pp. 1-4.

[27] K. H. Low, Factors affecting consumer resistance to PayPal mobile payment adoption: A study of generation $\mathrm{X}$ consumers, $\mathrm{Ph}$. D. dissertation, University of Tunku Abdul Rahman (UTAR), Malaysia, 2017.

[28] I. R. D. Luna, F. Montoro-Ríos, F. Liébana-Cabanillas, and J. G. D. Luna, NFC technology acceptance for mobile payments: A Brazilian perspective. Revista Brasileira de Gestão de Negócios, vol. 19, no. 63, pp. 82-103, 2017.

[29] E. T. Lwoga and N. B. Lwoga, User acceptance of mobile payment: The effects of user-center security, system characteristics and gender, The
Electronic Journal of Information Systems in Developing Countries (EJISDC), vol. 81, no. 3, pp. 1-24, 2017.

[30] R. Magnier-Watanabe, An institutional perspective of mobile payment adoption: The case of Japan, in Proceedings 47th Hawaii International Conference on System Sciences, Waikoloa, Hawaii, 2014, pp. 10431052.

[31] M. Mallika, M. M. Sulphey, and J. Prabhakaran, Perceptions and intentions of customers towards mobile banking adoption, The Journal Contemporary Management Research, vol. VIII., no. 1, pp. 83-101, 2014.

[32] J. C. Nunnally, Psychometric Theory (2nd ed.). New York: McGrawHill Book Company, 1978.

[33] J. L. Pinchot, S. Mishra, K. L. Paullet, and F. G. Kohun, Exploring barriers to adoption of mobile payment for university students: Lack of awareness, lack of availability, and perceived security risks, Issues in Information Systems, vol. 17, no. 3, pp. 20-30, 2016.

[34] P. Pourghomi and G. Ghinea, Managing NFC payment applications through cloud computing, in Proceedings 2012 International Conference for Internet Technology and Secured Transactions, London, 2012, pp. 772-777.

[35] Statista. (n.d.). Smartphone users in Saudi Arabia 2015-2022. [Online]. Available: https://www.statista.com/statistics/494616/smartphone-usersin-saudi-arabia. 